\title{
Novel role of VMP1 as modifier of the pancreatic tumor cell response to chemotherapeutic drugs
}

\author{
Marina Gilabert ${ }^{1,2,3,4}$, Maria Inés Vaccaro ${ }^{5}$, Martin E Fernandez-Zapico ${ }^{6}$, Ezequiel L Calvo ${ }^{7}$, \\ Olivier Turrini ${ }^{1,2,3,4}$, Véronique Secq ${ }^{1,2,3,4}$, Stéphane Garcia ${ }^{1,2,3,4}$, Vincent Moutardier ${ }^{1,2,3,4}$, \\ Gwen Lomberk $^{8}$, Nelson Dusetti ${ }^{1,2,3,4}$, Raul Urrutia ${ }^{8, \$}$, and Juan L lovanna ${ }^{1,2,3,4, \$}$ \\ ${ }^{1}$ Cancer Research Center of Marseille, Inserm U1068, Marseille, France \\ ${ }^{2}$ Institut Paoli-Calmettes, Marseille, France \\ ${ }^{3}$ Aix-Marseille University, Marseille, France \\ ${ }^{4}$ CNRS, UMR7258, F-13288, Marseille, France \\ ${ }^{5}$ Department of Pathophysiology, School of Pharmacy and Biochemistry, University of Buenos \\ Aires, Buenos Aires, Argentina \\ ${ }^{6}$ Schulze Center for Novel Therapeutics, Division of Oncology Research, Department of \\ Oncology, Mayo Clinic Cancer Center, Mayo Clinic, Rochester, USA \\ ${ }^{7}$ Molecular Endocrinology and Oncology Research Center, CHUL Research Center, Quebec, \\ Canada \\ ${ }^{8}$ Laboratory of Epigenetics and Chromatin Dynamics, Gastroenterology Research Unit, \\ Translational Epigenomics Program, Center for Individualized Medicine (CIM), Mayo Clinic, \\ Rochester, USA
}

\section{Abstract}

We hypothesized that inhibiting molecules that mediate the adaptation response to cellular stress can antagonize the resistance of pancreatic cancer cells to chemotherapeutic drugs. Toward this end, here, we investigated how VMP1, a stress-induced autophagy-associated protein, modulate stress responses triggered by chemotherapeutic agents in PDAC. We find that VMP1 is particularly overexpressed in poorly differentiated human pancreatic cancer. Pharmacological studies show that drugs that work, in part, via the endoplasmic reticulum stress response, induce VMP1 expression. Similarly, VMP1 is induced by known endoplasmic reticulum stress activators. Genetic inactivation of VMP1 using RNAi-based antagonize the pancreatic cancer stress response to antitumoral agents. Functionally, we find that VMP1 regulates both autophagy and chemotherapeutic resistance even in the presence of chloroquin, ATG5 or Beclin 1 siRNAs, or a Beclin 1-binding VMP1 mutant. In addition, VMP1 modulates endoplasmic reticulum stress independently of its coupling to the molecular and cellular autophagy machinery. Preclinical studies demonstrate that xenografts expressing an inducible and tractable form of VMP1 show

\$Corresponding authors: juan.iovanna@inserm.fr; Tel : (33) 491 828803; Fax: (33) 49182886083 or to urrutia.raul@mayo.edu; Tel : (1) 507-255-6138; Fax: (1) 507-255-6318.

Conflicts of interest: No potential conflicts of interest were disclosed. 
increased resistance to the gemcitabine treatment. These results underscore a novel role for VMP1 as a potential therapeutic target for combinatorial therapies aimed at sensitizing pancreatic cancer cells to chemotherapeutic agents as well as provide novel molecular mechanisms to better understand this phenomenon.

\section{Introduction}

VMP1, also known as TMEM49, was initially identified by our laboratory as a stressinducible gene in organs affected by acute inflammatory responses (Dusetti et al., 2002) or transient ischemic injury. Subsequent, studies demonstrated that basal levels of VMP1 expression are a characteristic of the homeostatic state of many healthy tissues (Dusetti et al., 2002). Careful structural-functional studies reveal that VMP1 is a transmembrane protein with six hydrophobic regions, which allows it to locate to the intracellular membranes of the endoplasmic reticulum (ER) and the Golgi apparatus (Dusetti et al., 2002). In these organelles, VMP1 appear to be necessary for the endoplasmic reticulum integrity as VMP1 deficient cells display pleiotropic defects in the secretory pathways and organelle biogenesis (Calvo-Garrido et al., 2008). Forced expression of the VMP1/EGFP fusion protein promotes the formation of intracytoplasmatic vacuoles in which VMP1/EGFP is integrated into the membranes of these vacuoles (Dusetti et al., 2002). More recently, these vacuoles have been identified to be autophagosomes (Ropolo et al., 2007) and the mechanistic role of VMP1 as a regulator of autophagy established (Calvo-Garrido and Escalante, 2010; Itakura and Mizushima, 2010; Lo Re et al., 2012; Ropolo et al., 2007; Tian et al., 2010; Vaccaro et al., 2008), including in a specific form of autophagy named zymophagy (Grasso et al., 2011). The subsequent discovery that VMP1 is both structurally and functionally conserved in a wide range or organisms suggests that processes supported by this protein have undergone evolutionary pressure to maintain homeostasis from caenorhabditis elegans to human. Besides, it association to ER, Golgi, and autophagosomes, VMP1 associates to the plasma membrane in several cell types where it interacts with the tight junction protein Zonula Occludens-1 protein (Sauermann et al., 2008) to help support tight junction formation and cell-cell contacts. Altogether, these data strongly suggest that VMP1 is a versatile protein, which is required to maintain the integrity and function of many membranous organelles in an evolutionarily conserved manner.

In the current study, we sought to further explore the biological significance of the association of VMP1 to altered endoplasmic reticulum functions that characterize certain human diseases, with a specific focus on pancreatic cancer. Key investigations, particularly performed during the last two decades, have advanced our knowledge of the defined genetic alterations which underly pancreatic cancer development, although the irreversible nature of these mutations has hindered the development of either effective diagnosis or therapy.

Surgery is the most effective treatment but the mean life expectancy of the 15-20\% of patients who present with resectable tumor is only 15-18 months (Sultana et al., 2007). Even for patients who are qualified for surgery, aggressive metastasis highly resistant to conventional chemotherapy and radiation therapy often occurs after the operation. Therefore, prognosis of pancreatic cancer is very poor, and the incidence almost equals with the mortality rate, with a 5-year survival of less than $3-4 \%$. Patients with locally advanced 
disease have 6-10 months of median survival, and patients with metastatic disease only have 3-6 months of median survival (O'Reilly, 2009). Chemotherapy and radiotherapy offer limited benefit in metastatic disease and in adjuvant setting for patients undergoing surgery (Burris et al., 1997). Remarkably, however, the molecular mechanisms by which PDAC cells become resistant remain poorly known. Thus, our laboratory have devoted significant efforts to understand how these cells acquire their highly resistant phenotype and to find novel mechanisms which can serve as targets for developing novel therapies to fight this dismal disease. In this regard, studies on the effects of ER stress on cancer have recently elicited significant attention since this response results in reduced protein translation, increased chaperone activity, and ultimately lead to apoptotic cell death. In fact, functional alterations in the endoplasmic reticulum (ER) deploy a distinct signaling network that coordinates adaptive and apoptotic responses. Accumulating evidence has implicated prolonged ER stress in the development and progression of many diseases, including cancer (Hersey and Zhang, 2008; Koumenis, 2006; Li and Lee, 2006; Ozcan and Tabas, 2012). Furthermore, a large body of literature indicates that many chemotherapeutic drugs, work at least in part, by eliciting an ER response that contributed to tumoral cell death (Denmeade and Isaacs, 2012; Herr and Debatin, 2001; Schonthal et al., 2011). Consequently, this data raises the possibility that manipulation of the ER stress using small drugs may contribute to the development of combinatorial therapies aimed at sensitizing PDAC cells to chemotherapeutic agents.

In this article, we report that VMP1 is overexpressed in human pancreatic cancer, which are associated with poor prognosis. Both cellular and in vivo assays demonstrate that VMP1 is inducible by several endoplasmic reticulum stressors in pancreatic cancer cells. Moreover, we demonstrate that VMP1 overexpression results in increased resistance to anticancer drugs using well-characterized cellular and preclinical animal models of pancreatic cancer. Mechanistically, we show that VMP1 overexpression is downstream of the ATF6 pathway, a well-characterized regulator of ER stress in many cell systems. Therefore, our observations in human pancreatic cancer when combined with studies in cell and animals reveal for the first time a role for VMP1 as a modifier of the response of tumoral cells to chemotherapeutic drugs, at least in part, due to its participation in ER stress pathways. We believe that this new knowledge must be taken into consideration for the design and evaluation of studies aimed at developing therapeutic interventions used in the management of this malignant disease.

\section{Material and Methods}

\section{Cell culture and viability}

MiaPaCa2, Panc1 and HeLa cells were cultured in DMEM containing 10\% heat-inactivated fetal bovine serum (FBS). BxPc3 was cultured in RPMI 1640 containing $10 \%$ heatinactivated FBS, $2 \mathrm{mmol} / \mathrm{L}$ glutamine. Cell viability was determined using the CellTiter 96 Aqueous One Solution Reagent (Promega, Charbonnières-les-Bains, France) or Countess ${ }^{\mathrm{TM}}$ cell counter (Invitrogen) according to the instructions of the manufacturer. 


\section{Transfections}

Seventy-five percent confluent MiaPaCa2, Panc1 or HeLa cells were transfected with the different small interfering RNAs (siRNA) using the X-tremeGENE siRNA Transfection Reagent (Roche, Basel, Switzerland) according to the instructions of the manufacturer. Twenty-four hours after transfection, cells were trypsinized and seeded at a density of $5,000 / \mathrm{cm}^{2}$. Transfection efficiency was monitored using a control fluorescent siRNA (Qiagen, Hilden, Germany).

\section{RNA interference}

Double-stranded RNA duplexes corresponding to human VMP1 (5'-

r(GGCAGAAUAUUGUCCUGUGdTdT), ATF6 (siATF6; 5' -

r(GAGUUGUCUGUGUGAUGAUAGUAdTdT), human Beclin 1 (siBeclin1; 5'r(CAGUUUGGCACAAUCAAUAdTdT), human Atg5 (siATG5; 5'r(GCAACUCUGGAUGGGAUUGdTdT), and a nontargeted control (5'UUCUCCGAACGUGUCACGUdTdT) were purchased from Qiagen (Hilden, Germany).

\section{Quantitative Real-Time Reverse Transcription PCR (qRT-PCR)}

Total cellular RNA was isolated using the TRIzol protocol (Invitrogen, Cergy Pontoise, France) and cDNAs were prepared from $1 \mu \mathrm{g}$ total RNA using ImProm-II kit (Promega, Charbonnières-les-Bains, France) following the manufacturer's instructions. Quantitative PCR was performed in a LightCycler (Roche Diagnostics, Meylan, France) using the SYBR Premix Ex Taq (Takara Bio, Lonza, Levallois-Perret, France). The following sense and antisense primers were used to amplify human VMP1 (sense, $5^{\prime}$ -

TATGCCAAACGAATCCAGCAG- $3^{\prime}$, and antisense, $5^{\prime}$ -

CCAGTCTGTTGCAAGTTTGCTG-3'); the amplicon size is $313 \mathrm{bp}$. For ATF6 the forward primer was $5^{\prime}$-GATAGACACTTATTACCACC-3' and the reverse was $5^{\prime}$ -

GGGTAGTCTAGTATTGTTTCC- $3^{\prime}$; the amplicon size is 281 bp. For CHOP, the forward primer was 5'-ATGAGGACCTGCAAGAGGTCC-3' and the reverse was $5^{\prime}$ TCCTCCTCAGTCAGCCAAGC-3'; the amplicon size is $136 \mathrm{bp}$. For GRP78, the forward primer was 5'-GTTCTTGCCGTTCAAGGTGG-3' and reverse was $5^{\prime}$ -

TGGTACAGTAACAACTGCATG-3'; the amplicon size is 181 bp. For human glyceraldehyde-3-phosphate dehydrogenase (GAPDH), used as a reference, the forward primer was 5'-GGGAAGCTCACTGGCATGGCCTTCC- $3^{\prime}$ and the reverse was 5'CATGTGGGCCATGAGGTCCACCAC-3'; the amplicon size is $322 \mathrm{bp}$ ).

\section{Immunoblotting}

Protein extraction was performed on ice using total protein extraction buffer: $50 \mathrm{mM}$ Hepes pH 7.5, $150 \mathrm{mM} \mathrm{NaCl}, 20 \%$ SDS, 1 mM EDTA, 1 mM EGTA, 10\% Glycerol, $1 \%$ Triton, $25 \mathrm{mM} \mathrm{NaF}, 10 \mu \mathrm{M} \mathrm{ZnCl}_{2}, 50 \mathrm{mM}$ DTT. Before lysis, Protease Inhibitor Cocktail 1/200 (Sigma, P8340), $500 \mu \mathrm{M}$ PMSF, $1 \mathrm{mM}$ Sodium Orthovanadate and $1 \mathrm{mM} \beta$ Glycerophosphate were added. Protein concentration was measured using a BCA Protein Assay Kit (Pierce Biotechnology). Protein samples $(80 \mu \mathrm{g})$ were denatured at $95^{\circ} \mathrm{C}$ and subsequently separated by $12.5 \%$ SDS-PAGE gel electrophoresis. After transfer to nitrocellulose membrane and blocking with BSA 1\%, samples were probed with the home- 
made VMP1 rabbit polyclonal antibody (Ropolo et al., 2007), grp78 and CHOP rabbit polyclonal antibodies (Santa Cruz Biotechnology), LC3 rabbit polyclonal antibodies (Cell Signaling), p62 mouse monoclonal antibody (BD Bioscience) and $\beta$-tubulin (Sigma) using SNAP i.d.i.e. protein detection system (Millipore).

\section{Establishment of VMP1/EGFP-inducible MiaPaCa2 cells}

$\mathrm{pVgRXR}$ and pIND plasmids were obtained from Invitrogen. The VMP1/EGFP cDNA (Dusetti et al., 2002) was cloned into the pIND vector to obtain the pIND-VMP1/EGFP vector. MiaPaCa2 cells were transfected with $10 \mu \mathrm{g}$ of $\mathrm{pVgRXR}$ vector, which contains the ecdysone nuclear receptor subunit. Clones were selected and tested for Ponasterone A (PonA, Invitrogen) responsiveness by transient transfection with pIND-VMP/EGFP reporter plasmid. Clones showing moderate expression were transfected with $10 \mu \mathrm{g}$ of the pINDVMP1/EGFP vector and selected in zeocin $(0.4 \mathrm{mg} / \mathrm{ml})$ and G418 $(0.4 \mathrm{mg} / \mathrm{ml})$. MiaPaCa2 clones were tested for VMP1-inducible expression after PonA $(10 \mathrm{mM})$ treatment by epifluorescence of the EGFP-fused protein. These double resistant clones were picked to generate a stable cell line expressing $\mathrm{pVgRXR}$ and $\mathrm{pIND}$-VMP1/EGFP and were cultured in the presence of zeocin $(0.05 \mathrm{mg} / \mathrm{ml})$ and G418 $(0.2 \mathrm{mg} / \mathrm{ml})$ (VMP1/EGFP-inducible $\mathrm{MiaPaCa} 2$ cells). The addition of PonA $10 \mathrm{mM}$ to the culture medium induces formation of the RXR/VgEcR heterodimer, which binds the hybrid ecdysone response element in the pIND vector and activates the expression of VMP1/EGFP.

\section{Transient transfection}

p_empty, $\mathrm{p}_{-} \mathrm{VMP} 1$ and $\mathrm{p} \_\mathrm{VMP} 1{ }^{\triangle \mathrm{BBD}}$ plasmids were previously reported (Ropolo et al., 2007). Transfection efficiency was more than $80 \%$ as judged by expression of the EGFPfusion protein. Sixteen hours after transfection, 10,000 cells/well were plated in 96 well plates and 16 hours later cells were treated with the anticancer drugs Rapamycin $(10 \mu \mathrm{M})$, Adriamycin $(10 \mu \mathrm{M})$, Staurosporin $(0.5 \mu \mathrm{M})$, Imatinib $(0.3 \mu \mathrm{M})$, Cisplatin $(125 \mu \mathrm{m})$ and with hypoxia $(0.2 \%)$ for $24 \mathrm{~h}$ and cell survival was estimated as described above.

\section{In vivo tumor generation}

Mouse PonA-inducible model: Sixty days delayed release pellets with PonA or vehicle (Innovative Research of America) were implanted subcutaneous in male BALB/c athymic nude mice 4-6 weeks old with a metal trocar. Implants were introduced one day before subcutaneous injection of VMP1/EGFP-inducible MiaPaCa2 cells. Subcutaneous tumors were induced in nude mice by injection of $5 \times 10^{6}$ inducible MiaPaCa2 cells in DMEM $10 \%$ FBS. Gemcitabine was administered intraperitonealy once every 3 days at $65 \mathrm{mg} / \mathrm{kg}$. Tumors were measured with external caliper and volume was calculated as $(4 \pi / 3) \times$ (width/2) $2 \times$ (length/2) as previously described (Gironella et al., 2007).

\section{Ki-67 immunostaining}

Slides were deparaffinized, hydrated, and placed in antigen retrieval citrate buffer $(\mathrm{pH} 6.0$; Dako North America) in a pressure cooker for 15 minutes. For Ki-67 staining, slides were blocked with avidin/biotin (Dako) for 10 minutes. Slides were then placed in $3 \% \mathrm{H}_{2} \mathrm{O}_{2}$ for 10 minutes followed by incubation in protein block (Dako) for 15 minutes. Slides were 
stained with Ki-67 (mouse anti-rat, 1:50; Dako) for $1 \mathrm{~h}$ followed by incubation with the secondary antibody and counterstaining. Ki-67-positive cells were counted in four random fields (x400 magnification). All slides were counted independently by two investigators blinded to the treatment groups.

\section{Patients and Tissue Microarray (TMA)}

PDAC samples were formalin fixed surgical specimens obtained from the Pathology Department of the Aix Marseille University. Tumors were diagnosed and classified according to Klöppel and colleagues criteria (Luttges et al., 2000). Briefly, well differentiated tumors have well or moderately differentiated duct-like structures and tubular glands, mucin production, less than 10 mitosis per $10 \mathrm{HPFs}$ and little to moderate nuclear polymorphism, whereas poor differentiated tumors are characterized by the presence of poorly differentiated glands with mucoepidermoid and pleomorphic structures, without mucin production, more than 10 mitosis per $10 \mathrm{HPFs}$, and with marked nuclear polymorphism and increased size. Histopathological grade was confirmed in all cases by two experienced pathologists (SG and VS). The procedure for construction of TMAs was as previously described (Charpin et al., 2012; Giusiano et al., 2011; Giusiano et al., 2010). Briefly, cores were punched from the selected paraffin blocks and distributed in new blocks, with two cores of $0.6 \mathrm{~mm}$ diameter for each tumor. TMA serial tissue sections were prepared 24 hours before immunohistochemical processing and stored at $4{ }^{\circ} \mathrm{C}$. The immunoperoxidase procedures were performed using an automated Ventana Benchmark XT autostainer. Measurements of immunoprecipitates densitometry in cores were assessed in individual core after digitization and "cropping" of microscopic images as previously reported (Charpin et al., 2012; Giusiano et al., 2011; Giusiano et al., 2010). Polyclonal rabbit antiserum to VMP1 against the peptide MAQSYAKRIQQRLNSEEKTK (residues 386-406) was obtained as previously reported (Ropolo et al., 2007) and used at 1:500 dilution. Specificity of the antibody was previously described (Grasso et al., 2011).

\section{Statistics}

Statistical analyses were performed using the Student t-test. All values were expressed as mean \pm SEM, with significance set at $\mathrm{p} \unlhd \mathbf{} \mathbf{0} .05$. qRT-PCR data are representative of at least 3 independent experiments repeated at least two times in each case. For VMP1 protein expression on TMA, the statistical test used was GLM (General Linear Mixed) model with contrast statement to test differences among the 4 population (SAS Institute Inc., Cary, NC, USA).

\section{Results}

\section{VMP1 is upregulated in human pancreatic cancer to participate in the response of pancreatic tumor cells to hypoxia and chemotherapeutic drug}

We examined the localization and expression of the VMP1 protein in human pancreatic cancer by IHC on a TMA containing 88 primary PDAC, 23 metastasis and 26 normal peritumoral tissues. Figure 1 shows that, in normal peri-tumoral pancreatic tissue, VMP1 protein is expressed at low levels in acinar cells (except for rare cases of isolated cells; Figure 1A, arrows). On the other hand, an increase in VMP1 expression was systematically 
detected in PDAC and in metastasis samples. To better characterize this phenomenon, we quantified the levels of VMP1 in relationship to the differentiation state of the tumors by classifying our samples into well-differentiated, poor differentiated and metastatic tumors. This analysis reveal a significant difference between peri-tumoral and well differentiated, poor differentiated and metastasis samples $(\mathrm{p}>0.001)$ as well as between well differentiated and poor differentiated ( $p>0.03$ ). However, no significant differences were found between well differentiated or poor differentiated tumors with metastasis (Figure 1B). Altogether these data suggest that VMP1 expression is induced in PDAC, associated to the poor prognosis of the tissues examined, and thus may likely modify the response of these tumors to treatment. To test this idea, we therefore treated $\mathrm{MiaPaCa} 2$ cells with anticancer drugs, including Rapamycin $(10 \mu \mathrm{M})$, Gemcitabine $(100 \mu \mathrm{M})$, Adriamycin $(10 \mu \mathrm{M})$, Staurosporin $(0.5 \mu \mathrm{M})$, Imatinib $(0.3 \mu \mathrm{M})$, Cisplatin $(125 \mu \mathrm{m})$. Parallel experiments involved exposing these cells to hypoxia $\left(0.2 \% \mathrm{O}_{2}\right)$ for $24 \mathrm{~h}$. The results of these experiments, shown in Figure 2 demonstrate that similar to the direct inducers of ER stress tested above, Rapamycin, Adriamycin, Cisplatin and hypoxia upregulated VMP1 expression. On the other hand, Gemcitabine, Staurosporin and Imatinib downregulated VMP1 expression (Figure 2). Thus, combined these experiments reveal that several ER stressors, which bear significance relevance to pancreatic cancer, induce VMP1. Our results also show that VMP1 induction shows certain level of selectivity to a subset of chemotherapeutic drugs. Thus, we subsequently, investigated the role of VMP1 in the chemotherapeutic response by these drugs, by evaluating the effect of knocking down VMP1 on the resistance of pancreatic cells to Imatinib, Cisplatin, Adriamycin, Staurosporin and Rapamycin in three tumoral cell lines, namely MiaPaCa2, Panc1 and HeLa cells. We observed that siVMP1 transfection (see Figure 2B) do not showed a significant effect on cell survival in the absence of any other treatment. However, Figure 3 demonstrate that RNAi-mediated downregulation of VMP1 decreases the cell resistance against all these treatments (Figure 3). Similar results were obtained with a second siRNA sequence against VMP1 (data not shown). Thus, congruent with the experiments shown above in Figure 1, 2 and 3, this data support the notion that VMP1 is upregulated in response to both hypoxia and to widely used chemotherapeutic drugs likely to support the development of resistance to these treatments.

\section{VMP1 behaves as a gene modifier of the response to Gemcitabine treatment in preclinical models of pancreatic cancer}

The in vitro experiments described above suggest a potential for VMP1 to act as a gene modifier of the pancreatic tumor cells response to chemotherapeutic treatment, particular in the subset of tumor that show a poor prognosis. Since Gemcitabine is the drug of choice for this type of tumors, we evaluated the antitumor effect of this drug in relationship to VMP1 expression. For this purpose, we developed a xenograft system using MiaPaCa2 cells engineered to express a PonA inducible VMP1/EGFP protein. Mice were treated with PonA or with placebo and randomly selected for treatment with either Gemcitabine or saline solution as control. Gemcitabine was administrated intraperitoneally once every 3 days for 5 consecutive weeks, starting after 1 week from the subcutaneous injection of the pancreatic tumoral cells. Figure 4 shows that VMP1 expressing tumors grew more than the placebotreated counterpart $\left(1365 \pm 122\right.$ vs. $\left.964 \pm 119 \mathrm{~mm}^{3}\right)$. Most notably, while Gemcitabine had a significant effect on saline-treated tumors $\left(1021 \pm 112 \mathrm{vs.} 224 \pm 39 \mathrm{~mm}^{3}\right)$, this effect was 
almost abolished in PonA-treated cells. In addition, immunohistochemical analysis of $\mathrm{MiaPaCa} 2$ tumor sections stained with $\mathrm{Ki}-67$ to measure proliferation index showed a significant increase in Ki-67 staining in the PonA-treated tumors in both, treated and untreated with Gemcitabine (Figure 4B and C). Altogether, our results reveal that enhanced expression of VMP1, which we know occurs in human pancreatic tumors from clinical series (Figure 4), modify the response to the widely used agent Gemcitabine. This data must be taken into consideration for evaluating VMP1 as either a potential target or a marker that modifies the sensitivity to of pancreatic cancer to chemotherapeutic treatment.

\section{VMP1 modifies the response to chemotherapeutic agents independently of its role in cell growth regulation or autophagy}

We evaluated whether the chemotherapeutic effects of VMP1 occur through the modification of either cell growth or autophagy. Since cell growth represent, in large part, a balance between cell proliferation and apoptosis we measured Brdu incorporation and caspase 3/7 activity in VMP1/EGFP-inducible MiaPaCa2 cells. No significant differences were obtained in both cell growths as estimated by cell counting none by measuring BrdU incorporation (supplementary Figure 1). Moreover, no differences were observed in caspase 3/7 activity (supplementary Figure 1). Thus, over-expression of VMP1 alone, as showed in Figure 2C), neither affects cell growth nor death in vitro. Nonetheless, in light of the results obtained with chemothepeutic drugs in vitro, it remain possible that enhanced levels of VMP1 modify cell growth under conditions in which pancreatic tumors cells are exposed to these agents. Indeed, the results of additional experiments using this type of agents show that VMP1 expression significantly increased cell viability after either hypoxia or treatment with single chemotherapeutic agents, namely Imatinib, Cisplatin, Adriamycin, Staurosporin or Rapamycin (Figure 5A). Thus, VMP1 appears to modulate pancreatic cell growth only in response to treatment. Due to the biomedical relevance of these results, we evaluated whether the effects of VMP1 as a modifier of chemotherapeutic responses can be accounted by its well-established cellular function, namely the regulation of autophagy. Consequently, we induced VMP1 expression with PonA while inhibiting autophagy flux by treating the cells either chemically (chloroquin $10 \mu \mathrm{M}$ ) or genetically through the RNAi-based inhibition of two well-known autophagy regulators such as siATG5 (see Figure 5A and C) and siBeclin1 (data not shown). Unexpectedly, we found that the protective effect of VMP1 against chemotherapeutic agents largely occurs independent of autophagy. These novel autophagy-independent effects of VMP1 were confirmed using a mutated VMP1 $\triangle \mathrm{BBD}$ construct carrying a deletion in its C-terminal BBD (Beclin 1 binding domain), which is crucial for its autophagy function (Ropolo et al., 2007). Figure 5B demonstrates that transfection of either VMP1 wild type or VMP1 ${ }^{\triangle \mathrm{BBD}}$ construct resulted in similar protective effect when MiaPaCa2 cells were treated by hypoxia, Imatinib, Cisplatin, Adriamycin, Staurosporin or Rapamycin. Thus, we conclude that the protective effects that enhanced expression of VMP1 have on chemotherapeutic drugs occurs independent of a direct role in either cell growth regulation or autophagy.

\section{VMP1 functions in the ATF6-dependent ER stress response}

Recently, elegant studies have demonstrated that response of the pancreas to ER stress is a defining feature of both pancreatic cancer and pancreatitis. ER stress has also been 
established as an important mechanism underlying the response of pancreatic tumors to chemotherapy. Thus, since VMP1 is an important player in these pancreatic diseases and, as shown here, this protein modifies the response to this type of drugs, we evaluated its mechanistic role in ER stress. Accordingly, we induced ER stress in MiaPaCa2 cells by the treatment with Tunicamycin $(3 \mu \mathrm{g} / \mathrm{ml})$, Brefeldin A $(5 \mu / \mathrm{ml})$, Thapsigargin $(500 \mathrm{nM})$ or Dithiothereitol $(1 \mathrm{mM})$ for $24 \mathrm{~h}$ and measured the expression of VMP1, grp78 and CHOP by both qRT-PCR and Western blotting. Indeed, we find that VMP1 mRNA and protein expression were induced by these ER stress inducer treatments (Figure 6). Notably, VMP1 upregulation coincided with the expression of grp78, an unfolded protein response chaperone, and CHOP, an ER stress induced gene, which levels were also enhanced in response to the treatments (Figure 6). Similarly, expression of the VMP1 mRNA was induced by the treatments in Panc1 and BxPC-3 human pancreatic cancer cells (data not shown). Combined these results, lead us to investigate whether the regulation of VMP1, is mediated by known ER stress pathways such as ATF6 and ATF4 (Kim et al., 2006). RNAibased experiments, demonstrate that downregulation of ATF6 does not induce change the levels of VMP1 mRNA in MiaPaCa2 cells. Notably, however, when ER stress was induced, VMP1 expression significantly decreased in siATF6-treated cells, indicating that VMP1 activation is mediated by this protein (Figure 6). In contrast, RNAi-based ATF4 knocking down did not induced changes in VMP1 mRNA expression either in untreated or in cells undergoing ER stress (data not shown). These results links, for the first time, the induction of VMP1 to the ATF-dependent ER response with selectivity for the ATF6 isoform. Thus, VMP1 appears to plays a wider role in regulating the function of intracellular membranous organelles, which like autophagy and ER stress, play a significant role in the pathobiology of pancreatic cancer.

\section{Discussion}

In this paper we report that the autophagy-associated protein VMP1 is induced by some ER stress inducing factors through the ATF6 transcription factor, by hypoxia and by some, but not all, antitumoral agents. We also find that VMP1 knocking down increases, whereas its forced over-expression decreases, the sensitivity to all tested antitumoral agents in an autophagy-independent manner. Finally, we demonstrated that VMP1 is overexpressed in PDAC, particularly in the poorly differentiated forms.

Several targeted therapies that have been tested in PDAC have not been successful in eradicating the disease nor in improving significantly overall survival. Possible reasons for such failure are the strong resistance of PDAC cells to chemotherapy and radiotherapy (Wong and Lemoine, 2009) and the presence of an extensive fibrotic stroma, which is believed to favor rapid tumor progression and to create a physical barrier against drug delivery and immune cell infiltration (Olive et al., 2009; Provenzano et al., 2012). Besides a very abundant stroma, PDAC histology is characterized by poor vascularization, indicating that pancreatic cancer cells must adapt to an unfavorable microenvironment, which is both nutrient and oxygen poor. The limited supply of oxygen and nutrients likely to underlie the rigorous selection of cells that will ultimately form the tumor. In fact, pancreatic cancer resistant cells activate a complex genetic program to resist to the stress induced by that adverse environment. Therefore, a key strategy for increasing the effect of treatment against 
PDAC could be to block the action of the stress factors activated in the PDAC. We speculated that VMP1 could be one of these factors because its expression in the pancreas is dependent of the ER stress and hypoxia as showed in Figures 2 and 6. The results presented in this paper support this notion since knocking down VMP1 decreases resistance to anticancer drugs while overexpression of this protein has the opposite effect.

Since VMP1 activation has been largely associated, although not exclusively, to autophagy (Calvo-Garrido and Escalante, 2010; Grasso et al., 2011; Itakura and Mizushima, 2010; Ropolo et al., 2007; Tian et al., 2010; Vaccaro et al., 2008), which may play a role in pancreatic cancer cell resistance (Grasso et al., 2012), we speculate that VMP1 could protect the cell by activating ER stress-, hypoxia- and antitumoral drugs-dependent autophagy. To our surprise, although VMP1 over-expression readily induces autophagy (Figure 2) in PDAC-derived cells as expected, the protective effect was not dependent of autophagy since blocking the autophagy flux by using chloroquin or siRNA against autophagy-dependent factors ATG5 and Beclin1, or by transfecting a Beclin 1 binding domain deficient form of VMP1, did not significantly influenced its protective effect (Figure 5). In other words, the protective effect of VMP1 against anti-tumoral drugs remains almost intact in these conditions. Because drugs used have very different intracellular targets, we presume that VMP1 defensive effect is based on the activation of a general, yet undetermined, defensive program. Another interesting point is that VMP1 is expressed in PDAC and it is associated with their poor prognosis. One possible explanation is that, as showed in Figure 4, its overexpression increases the resistance to the first line of treatment Gemcitabine. However, because tumoral growth was more important in tumors expressing high levels of VMP1 (Figure 4), independently of any treatment, we cannot exclude an additional yet unknown effect on cancer progression.

Expression of several stress proteins is activated in pancreatic as well as no pancreatic cancer cells and their effect is almost systematically associated to a protective effect, decreased sensitivity to cell death by anti-tumoral drugs and/or to cancer progression and metastasis (Cano and Iovanna, 2010). These stress proteins include heat shock proteins (Baylot et al., 2011; Song et al., 2008; Xia et al., 2012a; Xia et al., 2009; Xia et al., 2012b) but not exclusively (Feldman et al., 2005; Sandi et al., 2011; Walsh et al., 2011). Overall, our data, together with observations from other laboratories, support the hypothesis that stress-associated genes could be efficient targets to treat patients with PDAC.

In summary, the current study demonstrates that VMP1 levels are increased in human pancreatic tumors with poor prognosis. Enhanced VMP1 levels modify the response of pancreatic tumoral cells to well-known chemotherapeutic drugs both in vitro and in vivo. Mechanistically, we find that the role of VMP1 in this response occurs independently of direct effects of this protein either on cell growth, apoptosis, or autophagy. Additionally, functional experiments reveal for the first time that VMP1 participates in these phenomena, at least in part, through its novel role in the ER stress response. The participation of VMP1 in ER stress shows a defined selectivity for the ATF6 pathway. Together, these results not only identify a critical role for VMP1 in pancreatic cancer but also outline novel molecular mechanisms underlying it function. Finally, VMP1 could be a new therapeutic target to treating patients with a PDAC. 


\section{Supplementary Material}

Refer to Web version on PubMed Central for supplementary material.

\section{Acknowledgments}

This work was supported by grants from Ligue Contre le Cancer, INSERM and INCA to JI; by the National Institutes of Health Grants DK52913, the Mayo Clinic Center for Cell Signaling in Gastroenterology (P30DK084567), and the Translational Epigenomic Program, Center for Individualized Medicine (CIM), Mayo Clinic to RU; and by the Mayo Clinic SPORE in Pancreatic Cancer P50 CA102701 to MEF-Z. We thanks to P Spoto, K Sari, C Loncle, MN Lavaut and J Tardivel-Lacombe for their technical help and P Berthézène for statistical analysis.

\section{Bibliography}

Baylot V, Andrieu C, Katsogiannou M, Taieb D, Garcia S, Giusiano S, Acunzo J, Iovanna J, Gleave M, Garrido C, Rocchi P. OGX-427 inhibits tumor progression and enhances gemcitabine chemotherapy in pancreatic cancer. Cell Death Dis. 2011; 2:e221. [PubMed: 22012255]

Burris HA 3rd, Moore MJ, Andersen J, Green MR, Rothenberg ML, Modiano MR, Cripps MC, Portenoy RK, Storniolo AM, Tarassoff P, Nelson R, Dorr FA, Stephens CD, Von Hoff DD. Improvements in survival and clinical benefit with gemcitabine as first-line therapy for patients with advanced pancreas cancer: a randomized trial. J Clin Oncol. 1997; 15(6):2403-2413. [PubMed: 9196156]

Calvo-Garrido J, Carilla-Latorre S, Lazaro-Dieguez F, Egea G, Escalante R. Vacuole membrane protein 1 is an endoplasmic reticulum protein required for organelle biogenesis, protein secretion, and development. Mol Biol Cell. 2008; 19(8):3442-3453. [PubMed: 18550798]

Calvo-Garrido J, Escalante R. Autophagy dysfunction and ubiquitin-positive protein aggregates in Dictyostelium cells lacking Vmp1. Autophagy. 2010; 6(1):100-109. [PubMed: 20009561]

Cano CE, Iovanna JL. Stress proteins and pancreatic cancer metastasis. ScientificWorldJournal. 2010; 10:1958-1966. [PubMed: 20890585]

Charpin C, Tavassoli F, Secq V, Giusiano S, Villeret J, Garcia S, Birnbaum D, Bonnier P, Lavaut MN, Boubli L, Carcopino X, Iovanna J. Validation of an immunohistochemical signature predictive of 8year outcome for patients with breast carcinoma. Int J Cancer. 2012; 131(3):E236-243. [PubMed: 22120430]

Denmeade SR, Isaacs JT. Engineering enzymatically activated "molecular grenades" for cancer. Oncotarget. 2012; 3(7):666-667. [PubMed: 22837432]

Dusetti NJ, Jiang Y, Vaccaro MI, Tomasini R, Azizi Samir A, Calvo EL, Ropolo A, Fiedler F, Mallo $\mathrm{GV}$, Dagorn JC, Iovanna JL. Cloning and expression of the rat vacuole membrane protein 1 (VMP1), a new gene activated in pancreas with acute pancreatitis, which promotes vacuole formation. Biochem Biophys Res Commun. 2002; 290(2):641-649. [PubMed: 11785947]

Feldman DE, Chauhan V, Koong AC. The unfolded protein response: a novel component of the hypoxic stress response in tumors. Mol Cancer Res. 2005; 3(11):597-605. [PubMed: 16317085]

Gironella M, Seux M, Xie MJ, Cano C, Tomasini R, Gommeaux J, Garcia S, Nowak J, Yeung ML, Jeang KT, Chaix A, Fazli L, Motoo Y, Wang Q, Rocchi P, Russo A, Gleave M, Dagorn JC, Iovanna JL, Carrier A, Pebusque MJ, Dusetti NJ. Tumor protein 53-induced nuclear protein 1 expression is repressed by miR-155, and its restoration inhibits pancreatic tumor development. Proc Natl Acad Sci U S A. 2007; 104(41):16170-16175. [PubMed: 17911264]

Giusiano S, Cochet C, Filhol O, Duchemin-Pelletier E, Secq V, Bonnier P, Carcopino X, Boubli L, Birnbaum D, Garcia S, Iovanna J, Charpin C. Protein kinase CK2alpha subunit over-expression correlates with metastatic risk in breast carcinomas: quantitative immunohistochemistry in tissue microarrays. Eur J Cancer. 2011; 47(5):792-801. [PubMed: 21194925]

Giusiano S, Secq V, Carcopino X, Carpentier S, Andrac L, Lavaut MN, Allasia C, Bonnier P, Iovanna JL, Garcia S, Boubli L, Birnbaum D, Charpin C. Immunohistochemical profiling of node negative breast carcinomas allows prediction of metastatic risk. Int J Oncol. 2010; 36(4):889-898.

[PubMed: 20198333] 
Grasso D, Garcia MN, Iovanna JL. Autophagy in pancreatic cancer. Int J Cell Biol. 2012; 2012:760498. [PubMed: 22291707]

Grasso D, Ropolo A, Lo Re A, Boggio V, Molejon MI, Iovanna JL, Gonzalez CD, Urrutia R, Vaccaro MI. Zymophagy, a novel selective autophagy pathway mediated by VMP1-USP9x-p62, prevents pancreatic cell death. J Biol Chem. 2011; 286(10):8308-8324. [PubMed: 21173155]

Herr I, Debatin KM. Cellular stress response and apoptosis in cancer therapy. Blood. 2001; 98(9): 2603-2614. [PubMed: 11675328]

Hersey P, Zhang XD. Adaptation to ER stress as a driver of malignancy and resistance to therapy in human melanoma. Pigment Cell Melanoma Res. 2008; 21(3):358-367. [PubMed: 18476909]

Itakura E, Mizushima N. Characterization of autophagosome formation site by a hierarchical analysis of mammalian Atg proteins. Autophagy. 2010; 6(6):764-776. [PubMed: 20639694]

Kim R, Emi M, Tanabe K, Murakami S. Role of the unfolded protein response in cell death. Apoptosis. 2006; 11(1):5-13. [PubMed: 16374548]

Koumenis C. ER stress, hypoxia tolerance and tumor progression. Curr Mol Med. 2006; 6(1):55-69. [PubMed: 16472113]

Li J, Lee AS. Stress induction of GRP78/BiP and its role in cancer. Curr Mol Med. 2006; 6(1):45-54. [PubMed: 16472112]

Lo Re AE, Fernandez-Barrena MG, Almada LL, Mills L, Elsawa SF, Lund G, Ropolo A, Molejon MI, Vaccaro MI, Fernandez-Zapico ME. A novel AKT1-GLI3-VMP1 pathway mediates KRASinduced autophagy in cancer cells. J Biol Chem. 2012

Luttges J, Schemm S, Vogel I, Hedderich J, Kremer B, Kloppel G. The grade of pancreatic ductal carcinoma is an independent prognostic factor and is superior to the immunohistochemical assessment of proliferation. J Pathol. 2000; 191(2):154-161. [PubMed: 10861575]

O'Reilly EM. Pancreatic adenocarcinoma: new strategies for success. Gastrointest Cancer Res. 2009; 3(2 Suppl):S11-15. [PubMed: 19461915]

Olive KP, Jacobetz MA, Davidson CJ, Gopinathan A, McIntyre D, Honess D, Madhu B, Goldgraben MA, Caldwell ME, Allard D, Frese KK, Denicola G, Feig C, Combs C, Winter SP, IrelandZecchini H, Reichelt S, Howat WJ, Chang A, Dhara M, Wang L, Ruckert F, Grutzmann R, Pilarsky C, Izeradjene K, Hingorani SR, Huang P, Davies SE, Plunkett W, Egorin M, Hruban RH, Whitebread N, McGovern K, Adams J, Iacobuzio-Donahue C, Griffiths J, Tuveson DA. Inhibition of Hedgehog signaling enhances delivery of chemotherapy in a mouse model of pancreatic cancer. Science. 2009; 324(5933):1457-1461. [PubMed: 19460966]

Ozcan L, Tabas I. Role of endoplasmic reticulum stress in metabolic disease and other disorders. Annu Rev Med. 2012; 63:317-328. [PubMed: 22248326]

Provenzano PP, Cuevas C, Chang AE, Goel VK, Von Hoff DD, Hingorani SR. Enzymatic targeting of the stroma ablates physical barriers to treatment of pancreatic ductal adenocarcinoma. Cancer Cell. 2012; 21(3):418-429. [PubMed: 22439937]

Ropolo A, Grasso D, Pardo R, Sacchetti ML, Archange C, Lo Re A, Seux M, Nowak J, Gonzalez CD, Iovanna JL, Vaccaro MI. The pancreatitis-induced vacuole membrane protein 1 triggers autophagy in mammalian cells. J Biol Chem. 2007; 282(51):37124-37133. [PubMed: 17940279]

Sandi MJ, Hamidi T, Malicet C, Cano C, Loncle C, Pierres A, Dagorn JC, Iovanna JL. p8 expression controls pancreatic cancer cell migration, invasion, adhesion, and tumorigenesis. J Cell Physiol. 2011; 226(12):3442-3451. [PubMed: 21344397]

Sauermann M, Sahin O, Sultmann H, Hahne F, Blaszkiewicz S, Majety M, Zatloukal K, Fuzesi L, Poustka A, Wiemann S, Arlt D. Reduced expression of vacuole membrane protein 1 affects the invasion capacity of tumor cells. Oncogene. 2008; 27(9):1320-1326. [PubMed: 17724469]

Schonthal AH, Chen TC, Hofman FM, Louie SG, Petasis NA. Preclinical development of novel antiglioma drugs targeting the endoplasmic reticulum stress response. Curr Pharm Des. 2011; 17(23): 2428-2438. [PubMed: 21827419]

Song D, Chaerkady R, Tan AC, Garcia-Garcia E, Nalli A, Suarez-Gauthier A, Lopez-Rios F, Zhang XF, Solomon A, Tong J, Read M, Fritz C, Jimeno A, Pandey A, Hidalgo M. Antitumor activity and molecular effects of the novel heat shock protein 90 inhibitor, IPI-504, in pancreatic cancer. Mol Cancer Ther. 2008; 7(10):3275-3284. [PubMed: 18852131] 
Sultana A, Tudur Smith C, Cunningham D, Starling N, Tait D, Neoptolemos JP, Ghaneh P. Systematic review, including meta-analyses, on the management of locally advanced pancreatic cancer using radiation/combined modality therapy. Br J Cancer. 2007; 96(8):1183-1190. [PubMed: 17406358]

Tian Y, Li Z, Hu W, Ren H, Tian E, Zhao Y, Lu Q, Huang X, Yang P, Li X, Wang X, Kovacs AL, Yu L, Zhang H. C. elegans screen identifies autophagy genes specific to multicellular organisms. Cell. 2010; 141(6):1042-1055. [PubMed: 20550938]

Vaccaro MI, Ropolo A, Grasso D, Iovanna JL. A novel mammalian trans-membrane protein reveals an alternative initiation pathway for autophagy. Autophagy. 2008; 4(3):388-390. [PubMed: 18253086]

Walsh N, Larkin A, Swan N, Conlon K, Dowling P, McDermott R, Clynes M. RNAi knockdown of Hop (Hsp70/Hsp90 organising protein) decreases invasion via MMP-2 down regulation. Cancer Lett. 2011; 306(2):180-189. [PubMed: 21470770]

Wong HH, Lemoine NR. Pancreatic cancer: molecular pathogenesis and new therapeutic targets. Nat Rev Gastroenterol Hepatol. 2009; 6(7):412-422. [PubMed: 19506583]

Xia Y, Liu Y, Rocchi P, Wang M, Fan Y, Qu F, Iovanna JL, Peng L. Targeting heat shock factor 1 with a triazole nucleoside analog to elicit potent anticancer activity on drug-resistant pancreatic cancer. Cancer Lett. 2012a; 318(2):145-153. [PubMed: 22266185]

Xia Y, Liu Y, Wan J, Wang M, Rocchi P, Qu F, Iovanna JL, Peng L. Novel triazole ribonucleoside down-regulates heat shock protein 27 and induces potent anticancer activity on drug-resistant pancreatic cancer. J Med Chem. 2009; 52(19):6083-6096. [PubMed: 19754200]

Xia Y, Rocchi P, Iovanna JL, Peng L. Targeting heat shock response pathways to treat pancreatic cancer. Drug Discov Today. 2012b; 17(1-2):35-43. [PubMed: 21986108] 

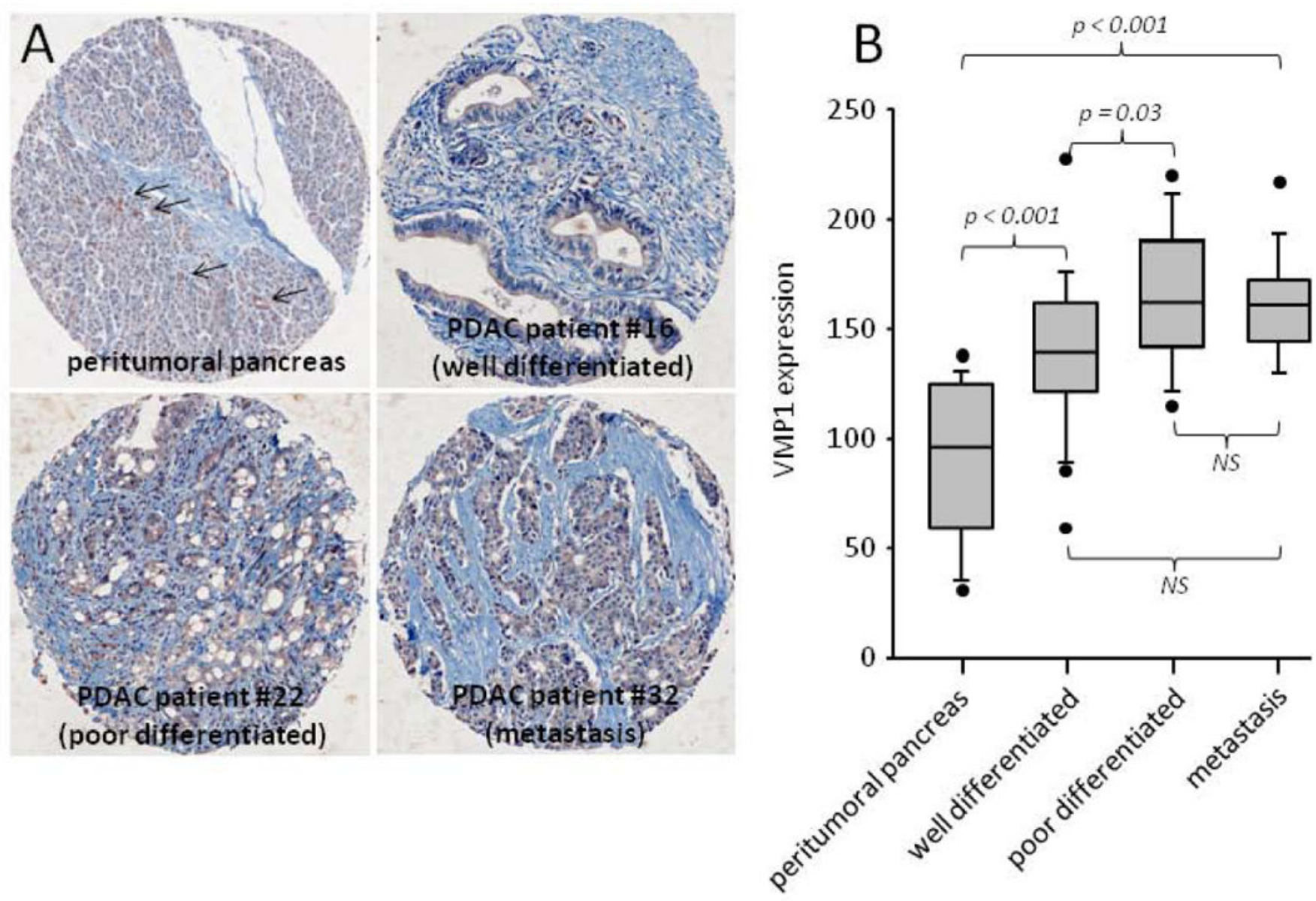

Figure 1. Expression of VMP1 in PDAC

VMP1 protein expression by IHC on a TMA containing 88 primary PDAC, 23 metastasis and 26 normal peritumoral tissues. Representative samples of peritumoral pancreas, well differentiated PDAC, poor differentiated and metastasis (A). Measurements of immunoprecipitates densitometry in cores was assessed as described in Material and Methods section. Values were represented in a box-and-whisker diagram. Statistical differences between groups were indicated (B). 

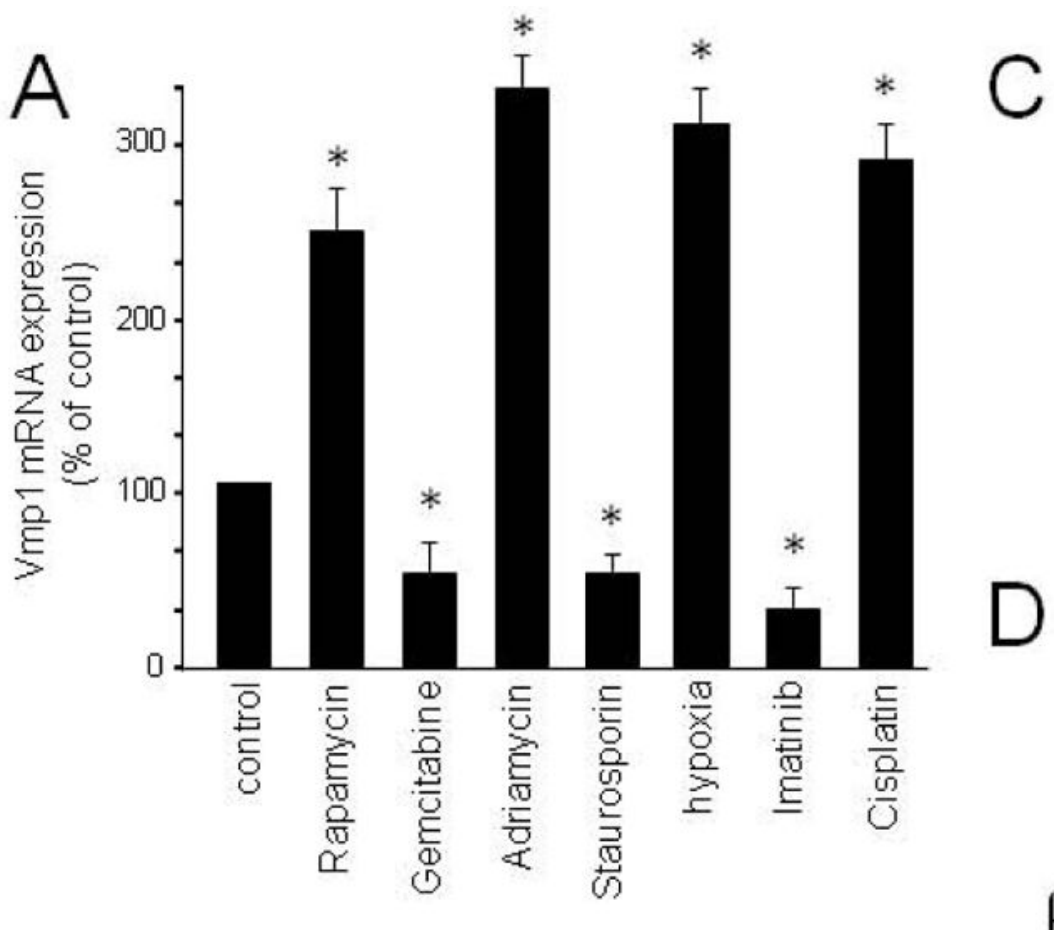

VMP1/EGFP

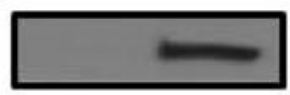

$\beta$-tubulin
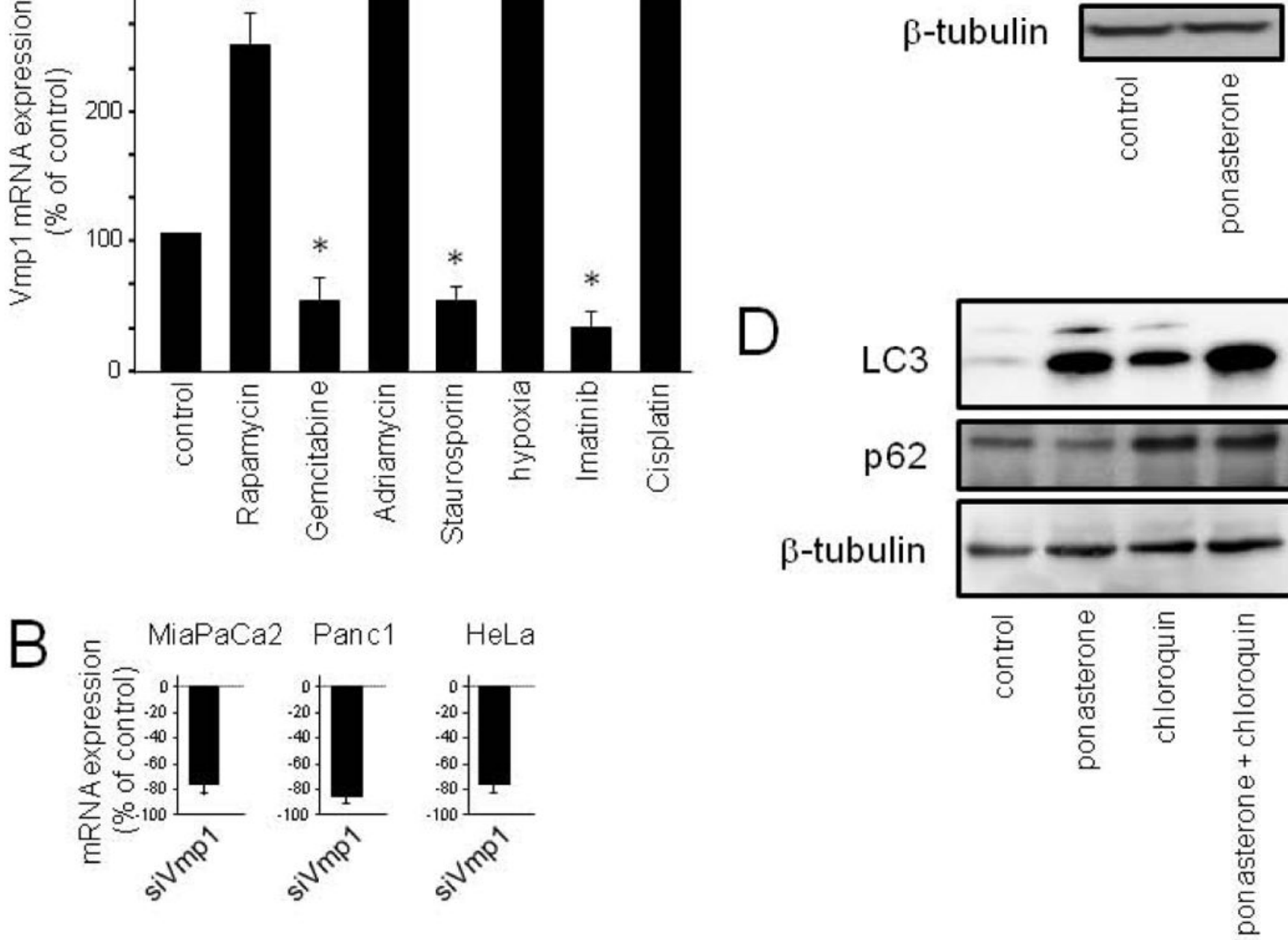

Figure 2. VMP1 is induced by anticancer drugs and hypoxia

MiaPaCa2 cells were treated with the anticancer drugs Rapamycin $(10 \mu \mathrm{M})$, Gemcitabine $(100 \mu \mathrm{M})$, Adriamycin $(10 \mu \mathrm{M})$, Staurosporin $(0.5 \mu \mathrm{M})$, Imatinib $(0.3 \mu \mathrm{M})$, Cisplatin (125 $\mu \mathrm{m})$ and with hypoxia $(0.2 \%)$ for $24 \mathrm{~h}$ and VMP1 mRNA expression was measured by qRTPCR (A). All values were expressed as mean \pm SEM, with significance set at $\mathrm{p} \unlhd 0.05$. qRTPCR data are representative of at least 3 independent experiments repeated at least two times in each case. MiaPaCa2, Panc1 and HeLa cells were transfected with siVMP1 and expression of its target was monitored using qRT-PCR (B). VMP1/EGFP-inducible $\mathrm{MiaPaCa} 2$ cell expresses detectable levels of VMP1/EGFP fusion protein in response to the PonA treatment (C). VMP1/EGFP-inducible MiaPaCa2 cell were treated with PonA alone or together with chloroquin for 24 hours. LC3, p62 and $\beta$-tubulin amounts were measured by western blot (D). 

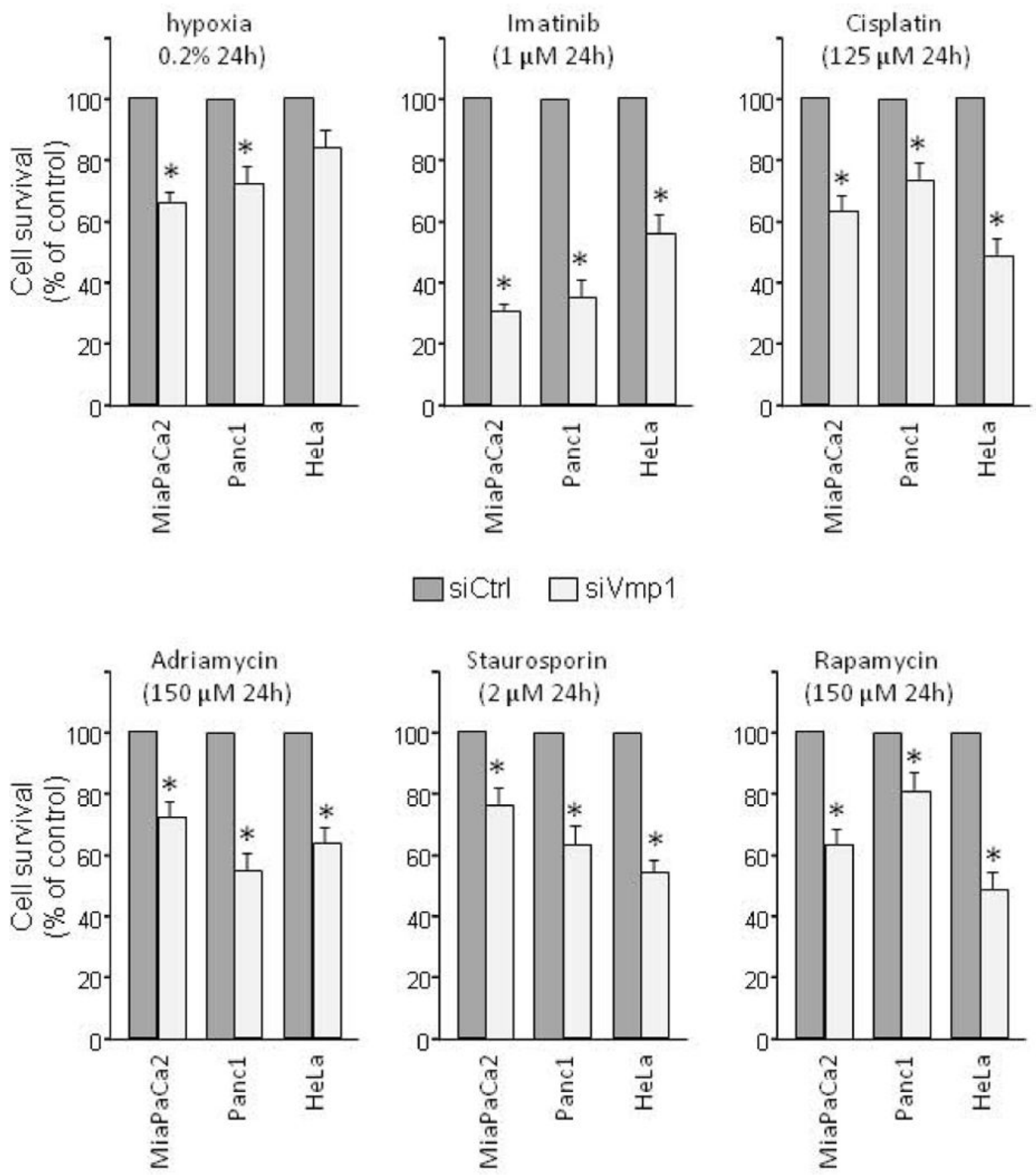

Figure 3. VMP1 knocking down sensitizes to hypoxia and anticancer drugs effects

MiaPaCa2, Panc1 and HeLa cells were transfected with siVMP1 or siCtrl and $24 \mathrm{~h}$ later treated with the anticancer drugs Rapamycin $(10 \mu \mathrm{M})$, Gemcitabine $(100 \mu \mathrm{M})$, Adriamycin $(10 \mu \mathrm{M})$, Staurosporin $(0.5 \mu \mathrm{M})$, Imatinib $(0.3 \mu \mathrm{M})$, Cisplatin $(125 \mu \mathrm{m})$ and with hypoxia $(0.2 \%)$. Cell survival analysis was performed using Countess ${ }^{\mathrm{TM}}$ cell counter (Invitrogen) on three independent samples for each condition. Data are means of triplicates \pm SEM. Statistically different from siCtrl-treated control (* p 40.05 ). 

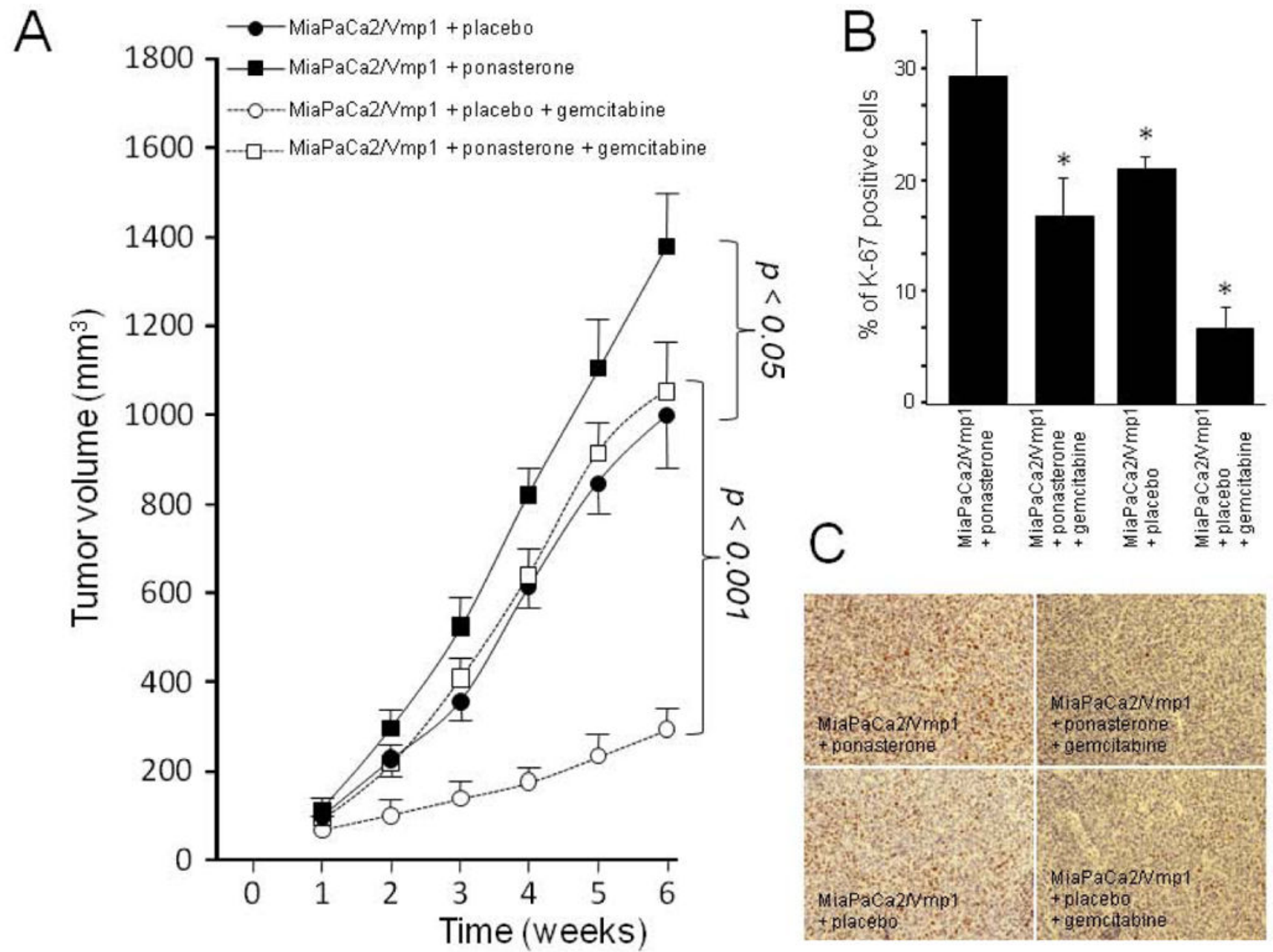

Figure 4. VMP1 over-expression increases resistance to Gemcitabine treatment in vivo Release pellets with PonA or vehicle were implanted subcutaneously in athymic nude mice 4-6 weeks old. Twenty hours later, subcutaneous tumors were induced in nude mice by injection of $5 \times 10^{6} \mathrm{VMP} 1$ inducible MiaPaCa 2 cells. Gemcitabine or saline was administered intraperitonealy once every 3 days at $65 \mathrm{mg} / \mathrm{kg}$ and tumor growth was measured with external caliper. Data are means of $n=6$ animal per group \pm SEM.

Statistically differences from PonA and placebo were indicated (A). Ki-67 staining. The percentage of Ki-67-positive cells was determined in four random fields (400x) for placebo and PonA-treated tumors with or without Gemcitabine (B). Representative tumors are shown (C); Tumors from animals treated with PonA show a significant increase in tumor cell proliferation in both, treated and untreated with Gemcitabine. 

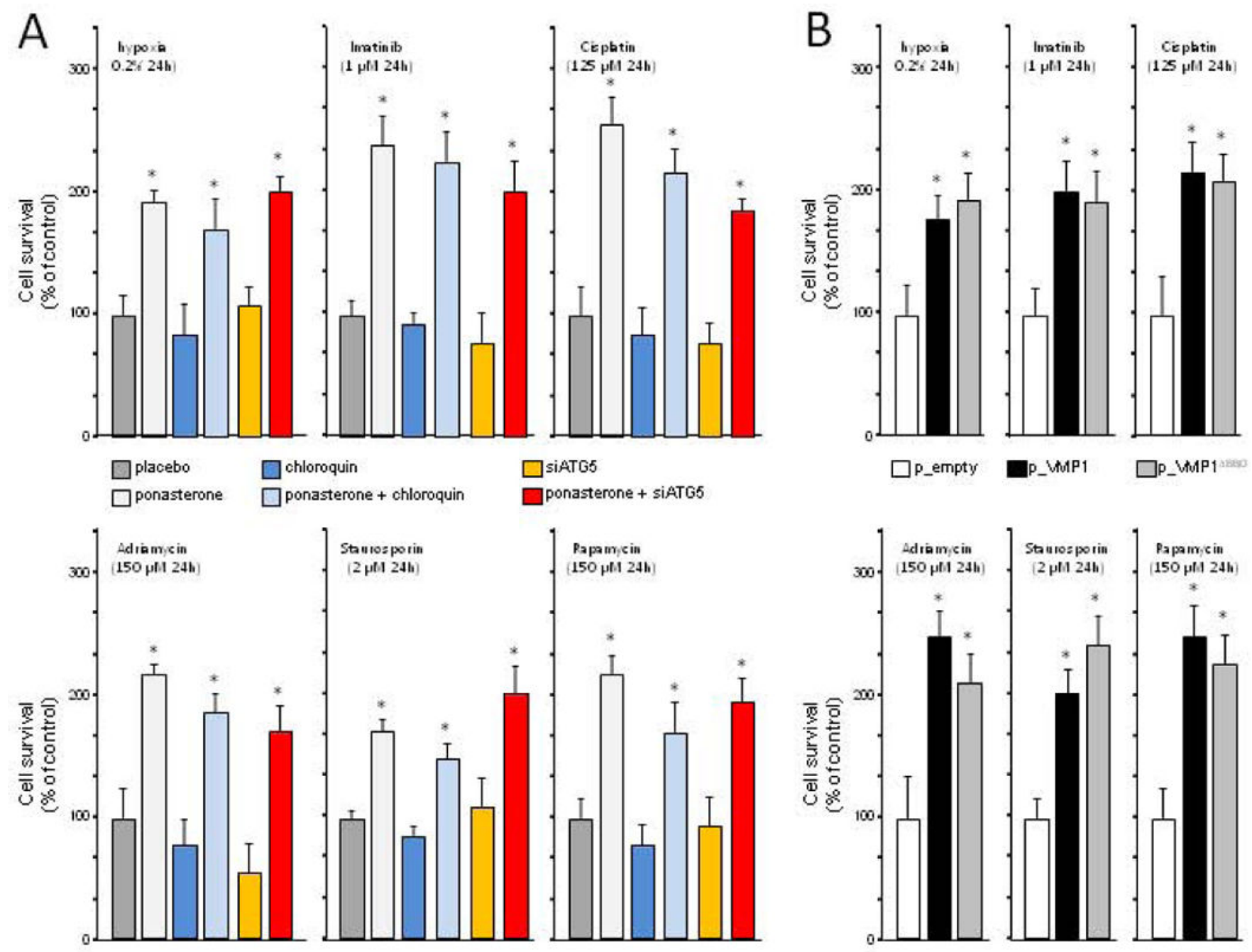

Figure 5. VMP1 over-expression protects from hypoxia and anticancer drugs effects independently of its autophagic-associated effect

(A) VMP1/EGFP-inducible MiaPaCa2 cells were treated with PonA or placebo, alone or in combination with chloroquin or siATG5, and $24 \mathrm{~h}$ later treated with the anticancer drugs Imatinib $(0.3 \mu \mathrm{M})$, Cisplatin $(125 \mu \mathrm{m})$, Adriamycin $(10 \mu \mathrm{M})$, Staurosporin $(0.5 \mu \mathrm{M})$,

Rapamycin $(10 \mu \mathrm{M})$ and with hypoxia (0.2\%). (B) MiaPaCa2 cells were transfected with pempty, VMP1 or VMP1 ${ }^{\triangle \mathrm{BBD}}$ plasmids and treated by hypoxia, Imatinib, Cisplatin,

Adriamycin, Staurosporin and Rapamycin es described above for $24 \mathrm{~h}$. Cell survival analysis was performed using Countess ${ }^{\mathrm{TM}}$ cell counter (Invitrogen) on three independent samples for each condition. Data are means of triplicates \pm SEM. Statistically different from siCtrl-treated control (* $\mathrm{p} \unlhd$ D.05). (C) MiaPaCa2 cells were transfected with siATG5 and expression of its target was monitored using qRT-PCR. 

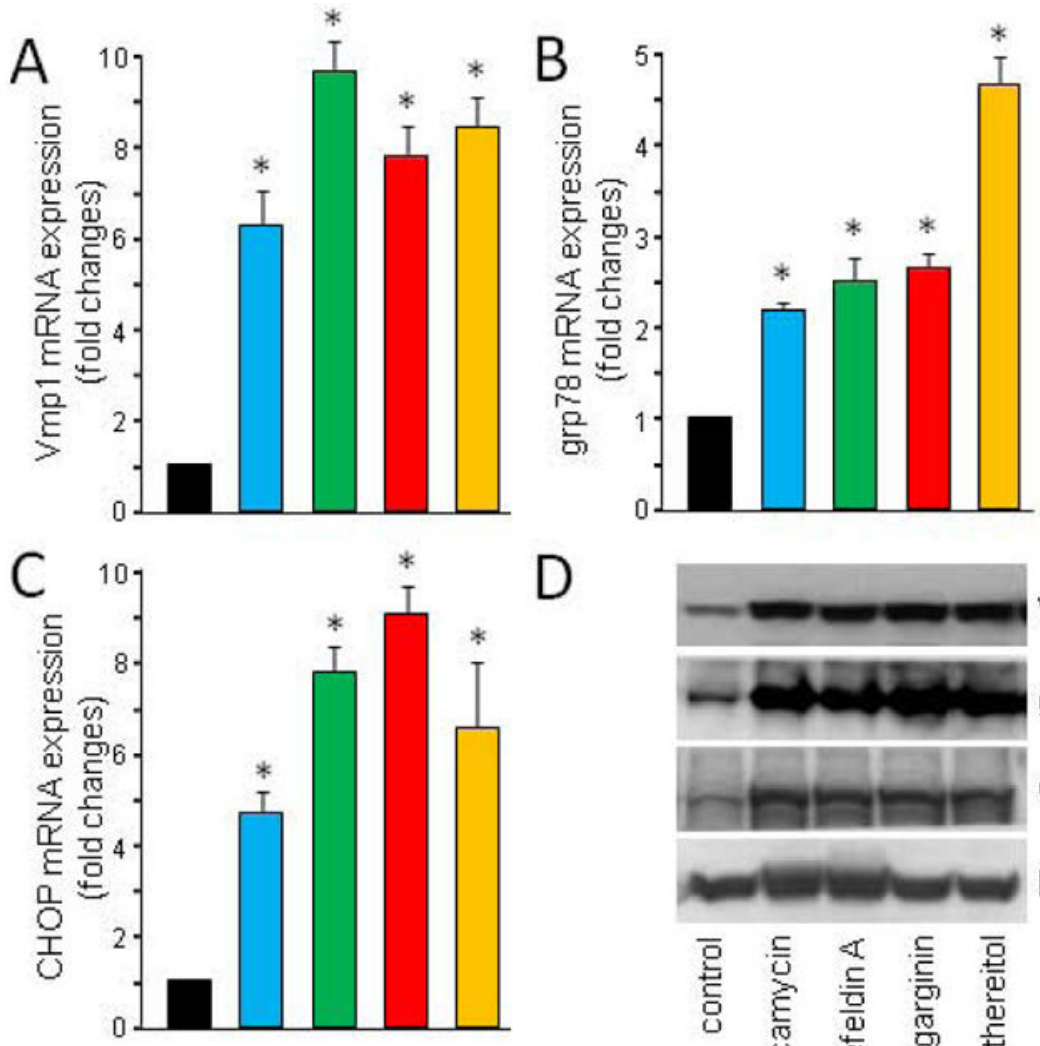

D
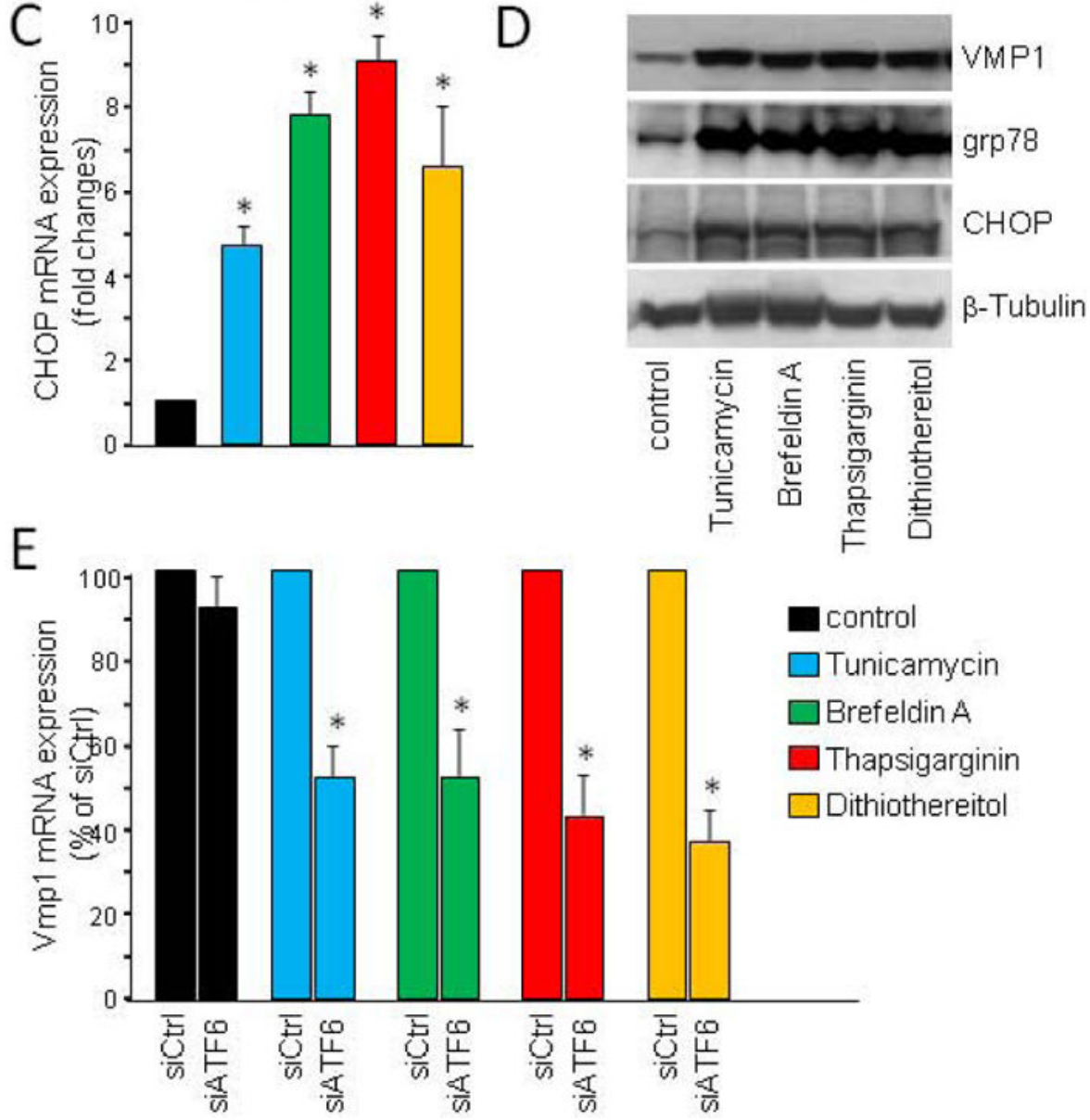

Figure 6. VMP1 is induced by endoplasmic reticulum stressors

MiaPaCa2 cells were treated with Tunicamycin $(3 \mu \mathrm{g} / \mathrm{ml})$, Brefeldin A $(5 \mu / \mathrm{ml})$, Thapsigargin $(500 \mathrm{nM})$ or Dithiothereitol $(1 \mathrm{mM})$ for $24 \mathrm{~h}$ and the expression of VMP1, grp78 and CHOP was determined by qRT-PCR (A, B and C) and Western blotting (D). (E) $\mathrm{MiaPaCa} 2$ cells were transfected with siCtrl or siATF6 and 24 later treated with the endoplasmic reticulum stressor for an additional $24 \mathrm{~h}$ period and the expression of VMP1 was determined by qRT-PCR. All values were expressed as mean \pm SEM, with significance set at $\mathrm{p} \$ 0.05$. qRT-PCR data are representative of at least 3 independent experiments 
repeated at least two times in each case. (F) MiaPaCa2 cells were transfected with siATF6 and expression of its target was monitored using qRT-PCR. 